\title{
Microbiota bacteriana da conjuntiva de doadores de córnea
}

\author{
Bacterial microbiota of the conjunctiva of donor corneas
}

\author{
Maria Emília Xavier dos Santos Araújo ${ }^{1}$ \\ Marinho Jorge Scarpi ${ }^{2}$
}

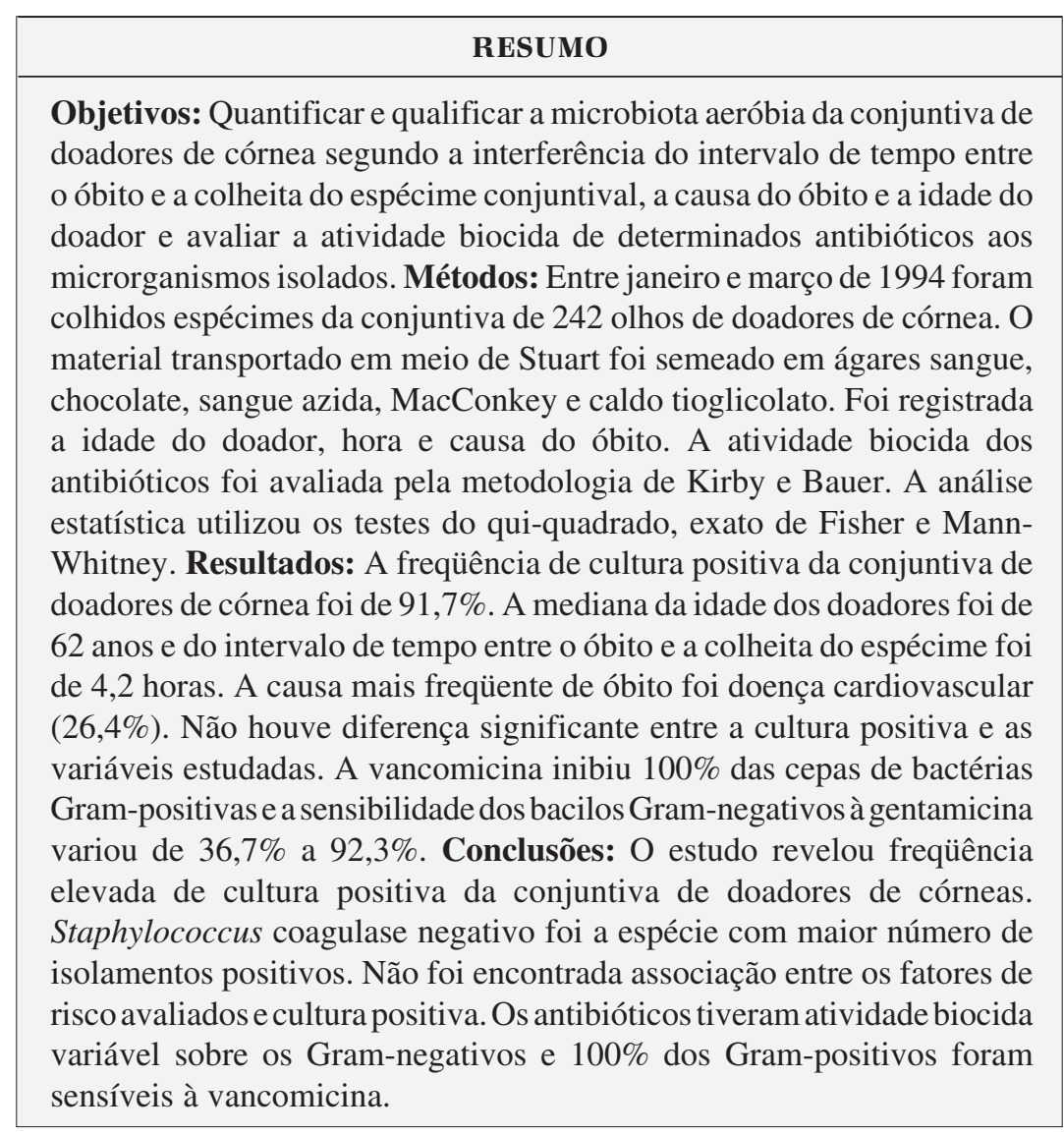

Descritores: Transplante de córnea; Córnea/microbiologia; Bactérias/isolamento e purificação; Doadores de tecidos; Conjuntiva/microbiologia; Infecções oculares bacterianas

Trabalho realizado no Departamento de Oftalmologia da Universidade Federal de São Paulo - UNIFESP e Hospital do Servidor Público Estadual de São Paulo HSPE.

${ }^{1}$ Doutora em Medicina pela Universidade Federal de São Paulo - UNIFESP, Coordenadora da Residência de Oftalmologia do Hospital do Servidor Público Estadual de São Paulo - HSPE.

${ }^{2}$ Livre-docente Professor do Departamento de Oftalmologia pela Universidade Federal de São Paulo UNIFESP.

Endereço para correspondência: Maria Emília Xavier dos Santos Araújo - Rua Huitacá, 96/103 - São Paulo (SP) CEP 04677-020

E-mail: emilia-araujo@uol.com.br

Recebido para publicação em 04.12.2003

Versão revisada recebida em 15.07.2004 Aprovação em 23.07.2004

Nota Editorial: Pela análise deste trabalho e por sua anuência na divulgação desta nota, agradecemos à Dra. Ana Luiza Höfling-Lima. 
Em outro estudo os autores encontraram um aumento de 4 a 15 vezes de Streptococcus spp e bactérias Gram negativas em doadores de córnea ${ }^{(6)}$. Este aumento foi verificado em outras pesquisas ${ }^{(3,5,7)}$, sugerindo que dever-se-ia à frequiência com que a necrópsia precede a enucleação ou ao tempo decorrido entre o óbito e a enucleação ${ }^{(8)}$.

Vários fatores têm sido associados à cultura positiva de olhos de doadores de córnea: causa do óbito, como septicemia $^{(9-10)}$, uso de respirador antes do óbito ${ }^{(11)}$, idade do doador ${ }^{(12-13)}$, intervalo de tempo entre o óbito e a enucleação ${ }^{(14)}$, técnica de remoção do tecido ${ }^{(15)}$, preparação imprópria, manipulação ou transporte do meio de preservação, contaminação pelos instrumentos, pela atmosfera ou pelo técnico no momento da excisão do botão corneal ${ }^{(16)}$ e tempo de preservação ${ }^{(17)}$.

$\mathrm{Na}$ avaliação da idade como fator de risco para cultura positiva do tecido corneal de doadores não foi demonstrada associação significante ${ }^{(12-13)}$.

A recomendação da "Eye Bank American Association" (EBAA) é que a enucleação do bulbo ocular seja realizada, de preferência, dentro das primeiras seis horas do óbito para evitar que as alterações metabólicas diminuam a viabilidade endotelial e pela possível associação com maior contaminação ${ }^{(18)}$. Quanto maior o intervalo de tempo entre o óbito e a enucleação, maior a probabilidade de contaminação do tecido ${ }^{(7,14)}$.

Como a completa esterilização do tecido doador não é sempre alcançada com as técnicas padrão dos bancos de olhos na enucleação (irrigação do bulbo com solução salina, anti-sepsia da pele e pálpebras com polivinilpirrolidona-iodo, uso de materiais estéreis, anti-sepsia das mãos e uso de luvas pelo técnico $)^{(15)}$ a adição de antibióticos aos meios de preservação da córnea visa diminuir a contaminação ${ }^{(19)}$. Não há consenso sobre qual antibiótico deva ser adicionado ao meio e qual sistema de armazenamento deva ser empregado imediatamente antes da remoção da córnea para transplante ${ }^{(20)}$.

Alguns autores avaliaram o efeito da penicilina, cefazolina e gentamicina, no meio de McCarey - Kaufman ${ }^{\circledR}$, in vitro, e concluíram que a gentamicina exerceu maior efeito antibacteriano contra os microrganismos estudados. A eficácia foi dependente da temperatura e do tempo de exposição ao antibiótico ${ }^{(21)}$.

Os antibióticos presentes no meio de McCarey-Kaufman ${ }^{\circledR}$ foram estreptomicina e penicilina ${ }^{(22)}$ e no K-Sol ${ }^{\circledR}$, Dexsol $^{\circledR}$ e Optisol $^{\circledR}$, gentamicina ${ }^{(23)}$. Atualmente os meios mais utilizados são o Optisol GS ${ }^{\circledR}$, com gentamicina e estreptomicina ${ }^{(23)}$ e o Likorol $^{\circledR}$, com penicilina, gentamicina e estreptomicina ${ }^{(24)}$.

A freqüência de cultura positiva da borda corneal, após preservação em meio com antibiótico, varia de 0,53 a 29\% ${ }^{(25-26)}$. Esta positividade reflete a emergência de microrganismos resistentes aos antibióticos presentes nos diferentes meios de preservação. Em uma amostra de 52 anéis córneo-esclerais foram encontrados $11,5 \%$ de contaminação em três meios de preservação $\left(\text { Optisol }^{\circledR} \text {, Optisol G-S }{ }^{\circledR} \text { e Likorol }^{\circledR}\right)^{(24)}$.

A endoftalmite bacteriana é complicação relativamente freqüente pós-transplante de córnea $(0,8 \%)$ se comparada com a incidência encontrada em cirurgia de catarata $(0,09 \%)^{(27)}$. O risco foi 22 vezes maior em receptores de córnea com cultura positiva $(1,3 \%)$, comparados com cultura negativa $(0,06 \%)$. No estudo de 55 casos de endoftalmite pós-transplante de córnea, 44 foram de origem bacteriana com cultura comprova$\mathrm{da}$; destes o mesmo microrganismo foi isolado do receptor e doador em $56,8 \%{ }^{(28)}$.

O objetivo desse trabalho é quantificar e qualificar a microbiota aeróbia da conjuntiva de doadores de córnea segundo o intervalo de tempo entre o óbito e a colheita do espécime conjuntival, da causa do óbito e da idade do doador e avaliar a atividade biocida de determinados antibióticos em relação aos microrganismos isolados.

\section{MÉTODOS}

Entre janeiro e março de 1994 foram colhidos espécimes do fundo de saco inferior da conjuntiva de 242 olhos de 121 doadores de córnea do Banco de Olhos de São Paulo, sem doença ocular visível à ectoscopia.

No momento da enucleação, foram registrados os seguintes dados do doador: idade, hora e causa do óbito, bem como a hora da colheita do espécime conjuntival de cada olho submetido ao estudo. Os doadores foram divididos em dois grupos de acordo com a variável estudada: idade - 0 a 64 anos e 65 anos; intervalo de tempo entre óbito e colheita das amostras zero a seis e maior que seis horas; causa do óbito - infecciosa (septicemia) e não infecciosa.

As colheitas do espécime foram feitas em ambientes não assépticos (local do óbito), com zaragatoa estéril, de maneira padronizada, com polivinilpirrolidona-iodo a $10 \%$ para antisepsia da pele da região periocular e pálpebras e utilizando-se instrumentos estéreis. Para transporte foi usado o meio de Stuart. Este material foi repicado nos meios de cultura: ágares sangue, sangue azida, chocolate, MacConkey e caldo tioglicolato. Não foi instilado nenhum colírio antibiótico ou solução antes da colheita.

As culturas foram avaliadas a cada 24 horas e consideradas negativas quando não foi observado crescimento nas placas após 48 horas de incubação a $35^{\circ} \mathrm{C}$, nem turvação no meio líquido após 72 horas. Nas placas com crescimento negativo, mas turvação do tioglicolato, procedeu-se o plaqueamento. Posteriormente as bactérias foram identificadas pelo método manual bioquímico.

A sensibilidade dos microrganismos aos antibióticos testados foi avaliada pelo método de difusão em ágar, conforme a metodologia de Kirby e Bauer modificada. (NCCLS-National Committee for Clinical Laboratory Standards -1993).

Para verificar a relação de dependência entre duas variáveis dicotômicas foi realizado o teste do Qui-quadrado de Pearson. O teste exato de Fisher foi utilizado quando pelo menos uma frequiência esperada foi menor do que cinco ou $\mathrm{n}<30$. O Teste de Mann-Whitney para comparação de duas amostras independentes e o método de Mantel-Haenszel que fornece a OR ajustada pela estratificação da relação exposição-efeito por uma terceira variável. Para todos os testes estatísticos, o nível de significância adotado foi de $\alpha<0,05$ ou $5 \%$. 


\section{RESULTADOS}

A freqüência de cultura positiva da conjuntiva dos doadores foi de $91,7 \%$ (222 olhos), com crescimento de um microrganismo, ou seja, cultura pura, em 63,2\% (153 olhos) e crescimento de mais de um microrganismo, ou cultura polimicrobiana, em 28,5\% (69 olhos). Foram 49,7\% de bactérias Gram positivas e $50,3 \%$ de Gram negativas (Tabela 1 ).

A mediana da idade dos doadores foi de 62 anos, com amplitude de variação de 1 a 95 anos. Os doadores $\geq 65$ anos foram encontrados em $47,1 \%$ da amostra. A associação entre a idade e a cultura positiva não foi estatisticamente significante $(\mathrm{P}=0,915)$ (Figura 1). A relação entre idade, separada em dois grupos (zero a 64 anos e 65 a 95 anos) e a cultura positiva também não foi significante $(\mathrm{P}=0,460)$.

As causas do óbito estão apresentadas na Figura 2. A associação entre cultura da conjuntiva e as causas de óbito dos doadores não foi significante $(\mathrm{P}=0,107)$.

A mediana do intervalo de tempo $(\Delta \mathrm{T})$ entre o óbito e a colheita dos espécimes da conjuntiva foi de 4,2 horas, com amplitude de variação de 40 minutos e 15 horas. $\mathrm{O} \Delta \mathrm{T}$ de seis horas ocorreu em $79,4 \%$. A associação entre cultura positiva e o $\Delta \mathrm{T}$ entre o óbito e a colheita nas seis primeiras horas e entre mais de seis e 15 horas não foi estatisticamente significante
$(\mathrm{P}=0,263)$. Quando analisamos a associação de cultura e o $\Delta \mathrm{T}$ entre o óbito e a colheita do espécime, estratificada por septicemia, houve uma significância limítrofe (tendência à significância) $(\mathrm{P}=0,653)$. Septicemia apresentou menor risco de cultura positiva nas seis primeiras horas pós-óbito.

A percentagem de sensibilidade das bactérias Gram positivas e negativas aos antibióticos testados está apresentada na tabela 2 e 3 .

\section{DISCUSSÃO}

A importância de avaliar a microbiota bacteriana de olhos de doadores de córnea está em monitorar a qualidade do tecido do banco de olhos e na associação da microbiota com endoftalmite pós-transplante, complicação devastadora em que a perda ocular ou visual é um resultado freqüente ${ }^{(13,28-29)}$. A incidência de endoftalmite pós-transplante de córnea varia de zero a $0,7 \%$, porém acredita-se que deva estar subestimada ${ }^{(27)}$. A cultura do tecido doador é um passo importante que pode evidenciar precocemente uma infecção que estaria por acontecer ${ }^{(29)}$.

A colheita da conjuntiva, escolhida para evitar dano ao epitélio da córnea, fornece suficiente informação sobre o tipo de contaminação bacteriana das córneas de doadores, como foi realizada neste estudo ${ }^{(3,7)}$.

\begin{tabular}{|c|c|c|c|}
\hline Staphyloccoccus coagulose negativa & $61(25,2)$ & $5 \quad(2,1)$ & $66(27,3)$ \\
\hline Staphylococcus aureus & $34(14,1)$ & $26(10,7)$ & $60(24,8)$ \\
\hline Enterococcus faecalis & $6(2,5)$ & $17(7,0)$ & $23(9,5)$ \\
\hline Streptococcus $\beta$ hemoliticus & $0 \quad(0,0)$ & $1 \quad(0,4)$ & $1(0,4)$ \\
\hline \multicolumn{4}{|l|}{ Bacilos Gram (-) } \\
\hline \multicolumn{4}{|l|}{ Fermentadores } \\
\hline Escherichia coli & $8 \quad(3,3)$ & $18(7,4)$ & $26(10,7)$ \\
\hline Klebsiella pneumoniae & $8 \quad(3,3)$ & $14(5,8)$ & $22(9,1)$ \\
\hline Citrobacter spp & $1 \quad(0,4)$ & $3(1,2)$ & $4 \quad(1,6)$ \\
\hline Morganella morganii & $1 \quad(0,4)$ & $1 \quad(0,4)$ & $2(0,8)$ \\
\hline Providencia spp & $0 \quad(0,0)$ & $3(1,2)$ & $3(1,2)$ \\
\hline Proteus vulgaris & $0 \quad(0,0)$ & $1 \quad(0,4)$ & $1(0,4)$ \\
\hline \multicolumn{4}{|l|}{ Não fermentadores } \\
\hline Pseudomonas aeruginosa & $10 \quad(4,1)$ & $20 \quad(8,3)$ & $30(12,4)$ \\
\hline Acinetobacter baumannii & $6 \quad(2,5)$ & $21 \quad(8,7)$ & $27(11,2)$ \\
\hline Pseudomonas spp & $1 \quad(0,4)$ & $2(0,8)$ & $3(1,2)$ \\
\hline Flavobacterium spp & $0 \quad(0,0)$ & $1 \quad(0,4)$ & $1 \quad(0,4)$ \\
\hline Stenotrophomonas maltophilia & $0 \quad(0,0)$ & $1 \quad(0,4)$ & $1 \quad(0,4)$ \\
\hline Sphingomonas paucimobilis & $0 \quad(0,0)$ & $1 \quad(0,1)$ & $1 \quad(0,4)$ \\
\hline
\end{tabular}




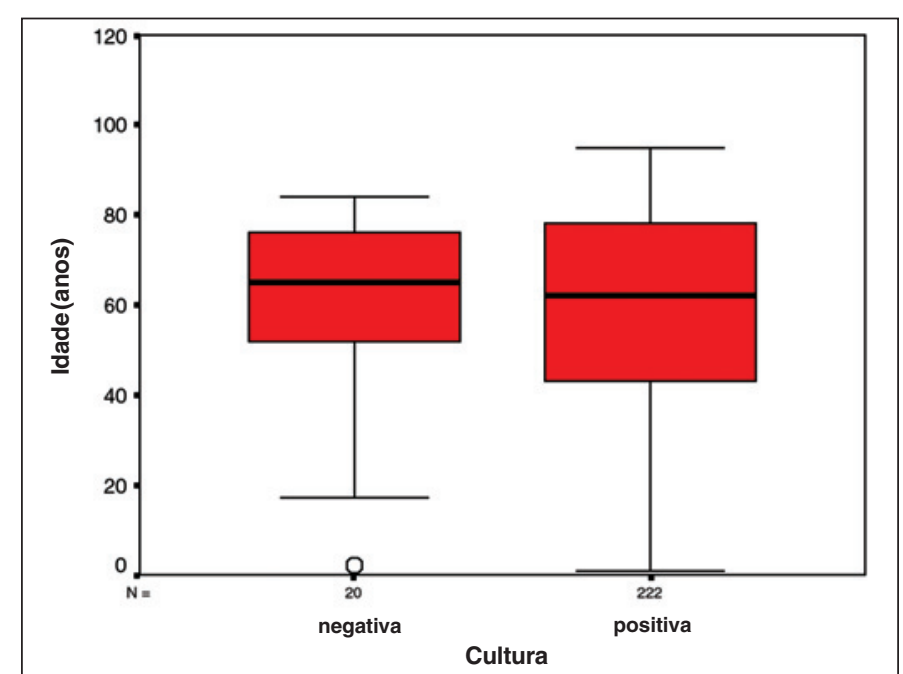

Figura 1 - Relação entre a positividade das culturas da conjuntiva e a idade dos doadores do Banco de Olhos de São Paulo. Teste de MannWhitney $(P=0,915)$

A freqüência de bactérias presentes na conjuntiva de olhos de doadores, nesta pesquisa, foi de $91,7 \%$ nos espécimes obtidos antes do uso de qualquer antibiótico prévio ou irrigação do globo ocular com solução salina. Resultado concordante com a literatura que registra 43 a $100 \%$ de positivida$\mathrm{de}^{(2-3)}$. A percentagem de positividade reflete a necessidade de tratamento prévio do bulbo ocular e preservação da córnea em meios com antibióticos para diminuir a contaminação.

No presente estudo, a bactéria com maior número de isolamentos positivos foi Staphylococcus coagulase negativa $(27,3 \%)$, não tendo sido identificada a espécie. Pesquisas ante-

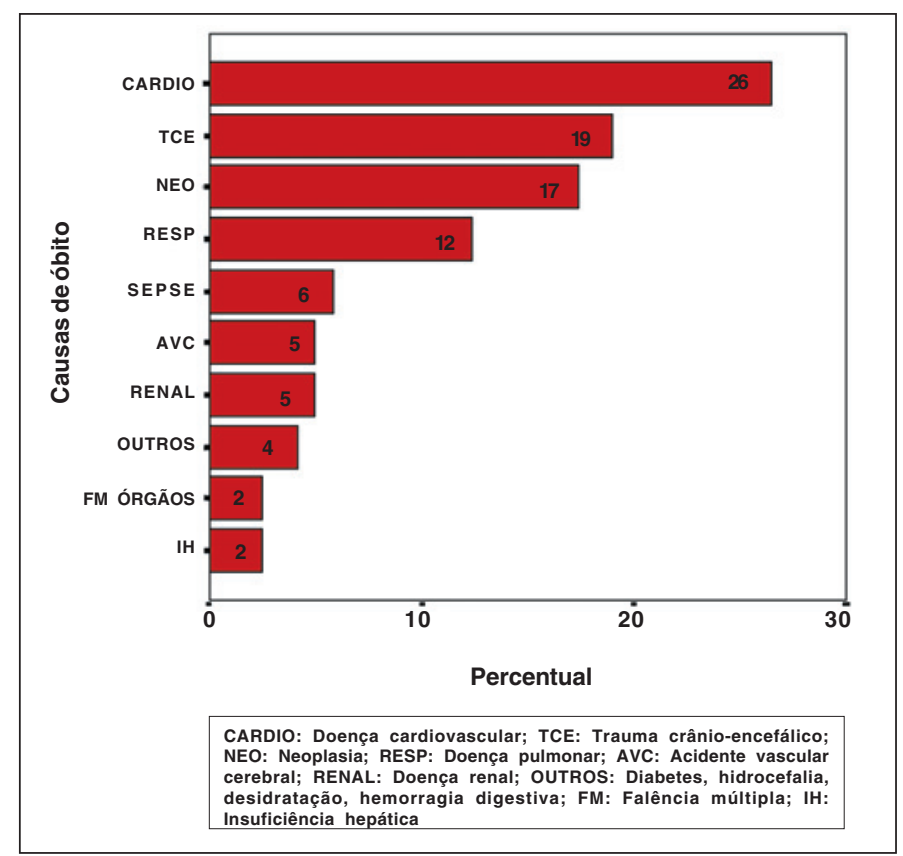

Figura 2 - Freqüência de causas de óbito dos doadores de córnea do Banco de Olhos de São Paulo riores isolaram entre 34 a 71,7\% de Staphylococcus epidermidis, a espécie mais encontrada entre as coagulase negati$\mathrm{va}^{(3,30)}$. Staphylococcus aureus foi isolado em $24,8 \%$, enquanto que a freqüência registrada na literatura está entre 1 e $36,3 \%$ (3,31).

Nesta pesquisa, foi encontrada freqüência elevada de bacilos Gram negativos, como Escherichia coli (10,7\%), Enterobacter spp $(10,4 \%)$ e Klebsiella pneumoniae (9,1\%), semelhante à encontrada por outros autores ${ }^{(3,5)}$. A Pseudomonas aeruginosa, associada a vários relatos de endoftalmite póstransplante de córnea, foi o bacilo Gram negativo mais comumente isolado $(12,4 \%)$ (Tabela 1$)$.

Acinetobacter spp têm sido identificadas como causa de infecção ocular ${ }^{(32)}$. Maior freqüência de colonização ocorre em pacientes hospitalizados, especialmente com Acinetobacter baumannii, espécie mais associada à infecção nosocomial ${ }^{(33)}$, o qual foi isolado em $11,2 \%$ neste estudo, sugerindo ser uma flora de origem hospitalar.

Nesta pesquisa a idade não foi um fator de risco para contaminação, mesmo em doadores idosos $(\geq 65$ anos) $(\mathrm{P}=0,460)$, não sendo critério de exclusão para o uso do tecido doador. É importante destacar que, mesmo em países desenvolvidos, $66 \%$ dos doadores estão acima da sexta década de vida ${ }^{(34)}$.

A septicemia foi responsável por 5,8\% das causas de óbito. Apesar da relação entre septicemia e a freqüência de cultura positiva não ter sido estatisticamente significante, quando estratificamos com o intervalo de tempo entre o óbito e a colheita do espécime, houve tendência à significância. A septicemia apresentou menor risco de cultura positiva nas primeiras seis horas $(\mathrm{P}=0,0653)$ quando comparada ao $\Delta \mathrm{T}$ após seis horas $(\mathrm{P}=0,079)$. Este resultado deve-se provavelmente ao fato de que os doadores estariam usando associação de antibióticos que poderia alterar a composição da microbiota indígena da superfície ocular.

O $\Delta \mathrm{T}$ entre o óbito e a colheita do espécime conjuntival, que correspondeu ao tempo entre o óbito e a enucleação, em $79,4 \%$ foi de seis horas, tempo estabelecido como o ideal para o melhor aproveitamento das córneas para transplante. Embora autores afirmem que quanto maior o $\Delta \mathrm{T}$ entre o óbito e a enucleação, maior a probabilidade de contaminação( ${ }^{(7)}$, a associação dessas duas variáveis, neste estudo, não foi estatisticamente significante $(\mathrm{P}=0,263)$.

$\mathrm{O}$ uso freqüente e prolongado de antibióticos facilita o desenvolvimento de cepas de bactérias resistentes aos agentes mais usados ${ }^{(35)}$. Torna-se necessária a realização periódica de testes de sensibilidade, a cada dois a três anos, para detectar tendências de resistência microbiana a antibióticos comumentes utilizados. Os resultados são de ajuda não somente em casos específicos, mas também como dados epidemiológicos ${ }^{(36)}$.

A suscetibilidade dos Staphylococcus coagulase negativa e aureus foram, respectivamente, 52,6\% e 50\% em relação à gentamicina (Tabela 2). A baixa sensibilidade demonstrada é preocupante, visto que essas bactérias estão entre as mais freqüentes causadoras de endoftalmite pós-transplante de córnea $^{(29)}$ e a gentamicina, juntamente com a estreptomicina, está presente no meio de preservação Optisol-GS ${ }^{\circledR}$, um dos 
mais utilizados atualmente. A penicilina é encontrada em associação com a gentamicina e estreptomicina, no Likorol ${ }^{\circledR}$, mas a sensibilidade dos Staphylococcus aureus à penicilina foi de apenas $11,7 \%$ nesta amostra. Estes resultados demonstraram que a penicilina e a gentamicina inibiram pobremente as cepas de Staphylococcus spp. Em outro estudo o Likorol ${ }^{\circledR}$ apresentou maior índice de contaminação (20\%) dos três meios estudados (Optisol ${ }^{\circledR}$, Optisol G-S ${ }^{\circledR}$ e Likorol $^{\circledR}$ ), embora não estatisticamente significante, sugerindo que a adição de penicilina ao meio de preservação não foi suficiente para aumentar sua eficácia antimicrobiana ${ }^{(26)}$.

Os laboratórios de Microbiologia não avaliam, rotineiramente, a sensibilidade da gentamicina em relação aos Streptococcus spp devido à pobre eficácia ${ }^{(37)}$ e por isso não foi testada no estudo em discussão. Os Streptococcus viridans, isolados em nove amostras, foram $100 \%$ sensíveis ao cloranfenicol e à van- comicina (Tabela 2). A endoftalmite por Streptococcus spp está associada a prognóstico reservado e pobre resultado visual.

A atividade biocida da tobramicina foi de $46,7 \%$ e da gentamicina foi $36,7 \%$ em relação à Pseudomonas aeruginosa (Tabela 3). A amicacina foi o antibiótico mais eficaz em relação à Pseudomonas aeruginosa, porém com atividade biocida de apenas $60 \%$. Em uma pesquisa foi observado que a amicacina diminuiu sua eficácia frente às bactérias Gram negativas, quando a suscetibilidade das Pseudomonas spp caiu de $100 \%$ para $55,5 \%{ }^{(38)}$. Registro recente demonstrou queda na atividade biocida in vitro da gentamicina e tobramicina a todos patógenos testados, no período de $15 \operatorname{anos}^{(39)}$.

Embora autores tenham registrado resistência de cepas de Staphylococcus coagulase negativa à vancomicina ${ }^{(40)}$, neste estudo esta droga inibiu $100 \%$ das bactérias Gram positivas, semelhante ao encontrado em outra pesquisa ${ }^{(5)}$.

\begin{tabular}{|c|c|c|c|c|}
\hline Ampicilina & NT & & NIT & \\
\hline & & & I & 00,9 \\
\hline Cefalotina & NT & NT & NT & 88,9 \\
\hline Clindamicina & 60,0 & 73,7 & NT & NT \\
\hline Cloranfenicol & 51,7 & 2,6 & 50,0 & 100,0 \\
\hline Eritromicina & 40,0 & 36,8 & 27,3 & 88,9 \\
\hline Gentamicina & 50,0 & 52,6 & NT & NT \\
\hline Oxacilina & 51,7 & 57,9 & NT & 88,9 \\
\hline Penicilina & 11,7 & 52,6 & 59,1 & 88,9 \\
\hline Rifampicina & 93,3 & 94,7 & NT & NT \\
\hline Sulfa + TMP* & 43,3 & 47,4 & NT & 66,7 \\
\hline Tetraciclina & 45,0 & 52,6 & NT & 77,8 \\
\hline Vancomicina & 100,0 & 100,0 & 100,0 & 100,0 \\
\hline
\end{tabular}

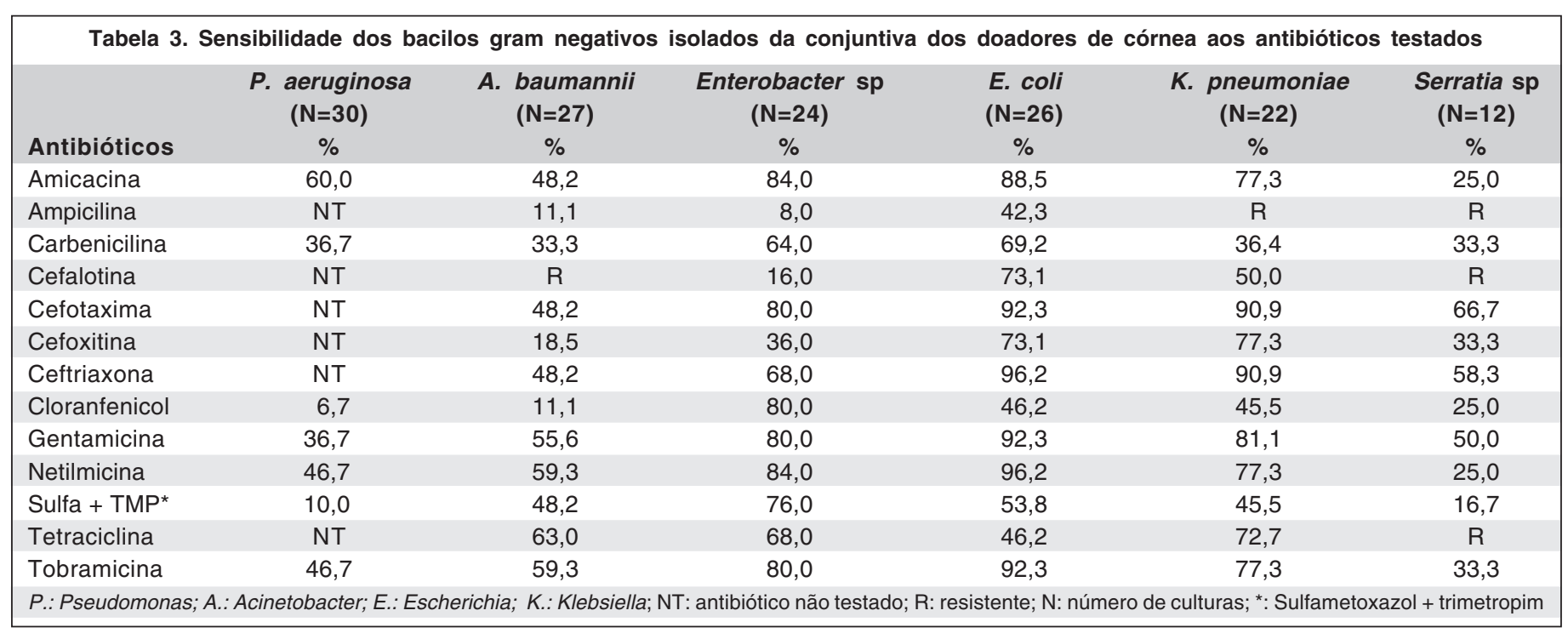




\section{CONCLUSÃO}

Este estudo revelou freqüência elevada de cultura bacteriana positiva $(91,7 \%)$ da conjuntiva de olhos de doadores antes de qualquer tratamento e preservação da córnea. A espécie bacteriana com maior número de isolamentos positivos foi Staphylococcus coagulase negativa (27,3\%).

As variáveis estudadas: causa do óbito, idade do doador, e intervalo entre o óbito e a colheita de amostras da conjuntiva não interferiram significantemente no número de culturas positivas e no tipo de isolamento bacteriano identificado.

Observou-se ainda que os cocos Gram positivos foram sensíveis à vancomicina e baixa sensibilidade de várias bactérias à gentamicina e à tobramicina, sugerindo uma reavaliação dos antibióticos presentes nos meios de preservação.

\section{ABSTRACT}

Purpose: To identify and qualify bacterial organisms in conjunctival tissue of donor corneas. To correlate the frequency of positive cultures with donor age, cause of death, and time from death to collection of conjunctival samples. To investigate bacterial susceptibility to specific antibiotics. Methods: Conjunctival samples obtained from the inferior conjunctival fornix of 242 eyes of cornea donors were collected between January and March, 1994. The samples were transferred to Stuart's medium and then inoculated into blood, acid blood, chocolate, McConkey agars, and thioglycolate broth. Donor age, time and cause of death were recorded. Bacterial susceptibility to antibiotics was tested using the diffusion method on agar modified by Kirby and Bauer. Statistical analysis was done using the chi-square, Fisher's exact and Mann-Whitney tests. Results: Microorganisms were identified in $91.7 \%$ of the samples. The most frequently isolated microorganism was coagulase-negative Staphylococcus $(27.3 \%)$. Time from death to collection of the conjunctival sample was on the average 4.2 hours. The most frequent cause of death was cardiovascular disease $(26.4 \%)$. The median donor age was 62 years. No significant correlation between positive cultures and the investigated variables was found. Vancomycin inhibited bacterial growth in $100 \%$ of Gram-positive microorganisms. The sensitivity of Gram-negative bacteria to gentamicin ranged from 36.7 to $92.3 \%$. Conclusion: The frequency of positive conjunctival cultures of donor corneas was $91.7 \%$. No significant statistical difference was found between positive cultures and the investigated parameters. Vancomycin inhibited the growth of Gram-positive bacteria in $100 \%$ of the cases and the sensitivity of Gram-negative bacteria to gentamicin varied.

Keywords: Cornea transplantation; Cornea/microbiology; Bacteria/isolation \& purification; Tissue donors; Conjuncti$\mathrm{va} /$ microbiology; Eye infections, bacterial

\section{REFERÊNCIAS}

1. Cabral JH, Farah AL, Santos MA, Belfort R, Mós EN, Farah ME. Microbiota anaeróbia e facultativa da conjuntiva normal de recém-nascidos. Arq Bras Oftalmol. 1993;56(3):138-45.

2. Rycroft P. Method for the preservation and sterilization of fresh donor material for full-thickness keratoplsty by gramicetin. Br J Ophthalmol. 1965;49:251-8.

3. Polack FM, Locatcher-Khorazo D, Gutierrez E. Bacteriologic study of "donor" eyes. Evaluation of antibacterial treatments prior to corneal grafting. Arch Ophthalmol. 1967;78(2)219-25.

4. Sperling S, Sorensen I. Decontamination of cadaver corneas. Acta Ophthalmol (Copenh). 1981;59(1):126-33.

5. Costa VP, Nicolela MT, Sawazaki E, Bechara SJ, José NK. Contaminação bacteriana em olhos doadores: estudo comparativo entre pacientes em coma "depassée" e cadáveres. Rev Bras Oftalmol. 1992;51(2):31-4.

6. Farrell PL, Fan JT, Smith RE, Trousdale MD. Donor cornea bacterial contamination. Cornea. 1991;10(5):381-6.

7. Schimmelpfennig B, Hürzeler R. Bacterial flora of stored human donor corneas after antibiotic treatment. Albrecht Von Graefes Arch Klin Exp Ophthalmol. 1977;202(3):181-5.

8. Badenoch PR, Alfrich SJ, Wedding TR, Coster DJ. Effectiveness of a decontamination method for donor corneas. Br J Ophthalmol. 1988;72(3):225-7.

9. Clark WM, Heaton KT, Snider GR, Reeve RB, Caskey PJ, Olson RJ. Donor eye contamination. Am J Ophthalmol. 1982;94(3):395-7.

10. Chittum ME, Grutzmacher RD, Oiland DM, Kalina RE. Contamination of corneal tissue from infected donors. Arch Ophthalmol. 1985;103(6):802-4.

11. Seedor JA, Stulting RD, Epstein RJ, Nay RE, Dreizen NG, Waring GO $3^{\text {rd }}$, et al. Survival of corneal grafts from donors supported by mechanical ventilation. Ophthalmology. 1987;94(2):101-8.

12. Gomes JA, Dana MR, Dua HS, Goren MB, Laibson P, Cohen EJ. Positive donor rim culture in penetrating keratoplasty. Cornea. 1995;14(5):457-62.

13. Borderie VM, Laroche L. Microbiologic study of organ-cultured donor corneas. Transplantation. 1998;66(1):120-3.

14. Armitage WJ, Easty DL. Factors influencing the suitability of organ-cultured corneas for transplantation. Invest Ophthalmol Vis Sci. 1997;38(1):16-24.

15. Lane SS, Mizener MW, Dubbel PA, Mindrup EA, Wick AA, Doughman DJ, et al. Whole globe enucleation versus in situ excision: a study of tissue trauma and contamination. Cornea. 1994;13(4):305-9.

16. Liesegang TJ, Robinson N, Jones DB. Modified tissue culture medium for corneal storage: I. Investigation of the effect of antibiotics on bacterial contamination. Arch Ophthalmol. 1984;102:619-24.

17. Antonios SR, Cameron JA, Badr IA, Habash NR, Cotter JB. Contamination of donor cornea: postpenetrating keratoplasty endophthalmitis. Cornea. 1991; 10(3):217-20.

18. Wilson SE, Bourne WM. Corneal preservation. Surv Ophthalmol. 1989; 33(4):237-59.

19. Yau CW, Busin M, Avni I, Kaufman HE. Antibacterial effect of donor corneas stored in gentamicin-enriched McCarey-Kaufman medium. Arch Ophthalmol. 1986;104(2):263-5.

20. Liesegang TJ, Robinson N, Jones DB. Modified tissue culture medium for corneal storage. II. Investigation of the effect of the corneaoscleral rim on bacterial contamination. Arch Ophthalmol. 1984;102(4):625-7.

21. Baum J, Barza M, Kane A. Efficacy of penicillin G, cefazolin, and gentamicin in M-K medium at 4 C. Arch Ophthalmol. 1978;96(7):1262-4.

22. McCarey BE, Kaufman HE. Improved corneal storage. Invest Ophthalmol Vis Sci. 1974;13(3):165-73.

23. Smith TM, Popplewell J, Nakamura T, Trousdale MD. Efficacy and safety of gentamicin and streptomycin in optisol-GS, a preservation medium for donor corneas. Cornea. 1995;14(1):49-55.

24. Rymer S, Scarpi MJ, Kwitko S, Alves LS. Comparação entre a eficácia antimicrobiana de três diferentes meios de preservação de córnea. Arq Bras Oftalmol. 1996;59(5):438-42.

25. Hagenah M, Bohnke M, Engelmann K, Winter R. Incidence of bacterial and fungal contamination of donor corneas preserved by organ culture. Cornea. 1995;14(4):423-6.

26. Mathers WD, Lemp MA. Corneal rim cultures. Cornea. 1987;6(3):231-3. 
27. Aiello LP, Javitt JC, Canner JK. National outcomes of penetrating keratoplasty. Risks of endophthalmitis and retinal detachment. Arch Ophthalmol. 1993; 111(4):509-13.

28. Kloess PM, Stulting RD, Waring GO 3rd, Wilson LA. Bacterial and fungal endophtalmitis after penetrating keratoplasty. Am J Ophthalmol. 1993;115(3): 309-16.

29. O'Day DM. Diseases potentially transmitted through corneal transplantation. Ophthalmology. 1989;96(8):1133-8.

30. Rollins HJ Jr, Stocker FW. Bacterial flora and preoperative treatment of donor corneas. Am J Ophthalmol. 1965;59:247-9.

31. Richards RD, Catzen M. Statistics of eye collections. Ann Ophthalmol. 1975; 7(2):221-4.

32. Prashanth K, Ranga MP, Rao VA, Kanungo R. Corneal perfuration due to Acinetobacter junii: a case report. Diag Microbiol Infect Dis. 2000;37(3):215-7.

33. Bergogne-Berezin E, Towner KJ. Acinetobacter spp. as nosocomial pathogens: microbiological, clinical, and epidemiological features. Clin Microbiol Rev. 1996;9(2):148-65.

34. Williams KA, Muechlberg SM, Lewis RF, Coster DJ. Influence of advanced recipient and donor age on the outcome of corneal transplantation. Br J Ophthalmol. 1997;81(1):835-9.

35. Gelender H, Rettich C. Gentamicin-resistant Pseudomonas aeruginosa corneal ulcers. Cornea. 1984;3(1):21-6.

36. Jensen HG, Felix C. In vitro antibiotic susceptibilities of ocular isolates in North and South America. In Vitro Antibiotic Testing Group. Cornea. 1998; 17(1):79-87.

37. Baer JC, Nirankari VS, Glaros DS. Streptococcal endophthalmitis from contaminated donor corneas after keratoplasty. Clinical and laboratory investigations. Arch Ophthalmol. 1988;106(4):517-20.

38. Wakisaka E, Ferreira MA, Rocha FJ, Freitas LL, Guidugli T, Lima ALH. Cultura de material provindo de úlceras de córnea em laboratório de referência. Arq Bras Oftalmol. 1990;53(5):196-200.

39. Chalita MR, Höfling-Lima AL, Paranhos A Jr, Schor P, Belfort R Jr. Shifting trends in vitro antibiotic susceptibilities for common ocular isolates during a period of 15 years. Am J Ophthalmol. 2004;137(1):43-51.

40. Schwalbe RS, Stapleton JT, Gilligan PH. Emergence of vancomycin resistance in coagulase-negative Staphylococci. N Engl J Med. 1987;316(15):927-31. 